\title{
AESTHETICIZATION OF THE LIVING ENVIRONMENT AS THE BASIS OF DESIGN ACTIVITY OF DESIGNERS
}

\author{
Evelina V. Michailova ${ }^{1 \star}$, Larisa A. Sakmarova ${ }^{2}$, Akhmetova P. Svetlana ${ }^{3}$, Olga P. \\ Andreeva ${ }^{4}$ \\ ${ }^{1}$ Assos. Prof., Chuvash State University named after I.N. Ulyanov, Russia, evelki38@yandex.ru \\ ${ }^{2}$ Assos. Prof, Chuvash State University named after I.N. Ulyanov, Russia, lara.sakmarova@mail.ru \\ ${ }^{3}$ Assos. Prof., Chuvash State University named after I.N. Ulyanov, Russia, ahsvetsvet@mail.ru \\ ${ }^{4}$ Assos. Prof., Chuvash State University named after I.N. Ulyanov, Russia, olyaokt@mail.ru \\ ${ }^{*}$ Corresponding Author
}

\begin{abstract}
This article examines the processes of aestheticization of the living environment through the use of elements of decorative and applied art in everyday life, which are now becoming universal and very ambiguous. The problems of interaction between the living environment and people are actualized against the background of typifications of the urban approach as phenomena of loss of individuality and existential need for beauty. The necessity of using tools for aestheticizing space in the design of a residential environment in order to create a comfortable and safe environment as a fundamental basis for the existential development of the individual is justified and activities of the designer. The authors focus on the emotional saturation of space with the help of artistic means. The article summarizes the systematic, private and psychological aspects of interaction between the environment and the person using works of decorative and applied arts. The authors describe in detail the option of creating such an interaction on a specific example of student work.
\end{abstract}

Keywords: living environment, aestheticization, decorative and applied creativity, educational process, emotional perception, space, individuality, design.

\section{INTRODUCTION}

Decorative art has become one of the most important types among other visual arts, as it is directly related to the human living environment. Currently, works of decorative art are gaining importance as a universal plastic and space-time categories, which, on the one hand, interact with the pictorial and graphic line, and on the other hand, with the environment, creating connections with the spatial and subject content and architecture. From the point of view of morphology, the structural characteristics of decorative and applied art and design are largely similar, because both types are based on the methods of artistic design. Modern decorative creativity in the context of the development of a wide variety of materials, techniques and technologies allows you to create artistic images of high meaningful significance. At the same time, the main function of works of decorative art remains to be aesthetic, which subtly induces the introduction of material objects to the world of spiritual values.

In the dictionary of the Russian language, aestheticization is understood as "giving something a beautiful external form". Aestheticization as a sensual manifestation of a person in any activity should be based on his formed aesthetic feelings. Aesthetic feelings are understood as an emotional state that arises in the process 
of contemplation, admiring the phenomena of reality or works of art; it is an individual experience caused by this process of perception, and manifest as feelings of the beautiful or sublime, tragic or comic ones.

\section{STATEMENT OF THE PROBLEM}

The active introduction of standard construction from the mid-60s of the 20th century was the reason for the artistic unification of the housing environment. At the beginning of the XX century, William Morris proposed to organically combine utilitarian and artistic principles in design activities, which would include not only fine arts, but also household items. The formation of an understanding begins that beauty should be created not only for contemplation and admiring; it should fully enter into human existence. Aesthetics is no longer perceived only as a part of artistic creativity, but becomes a necessary component of human life itself, thus there is a tendency to form individual forms and conditions of people's social life. In accordance with this, the motivating moment of environmental research is to ensure individuality in the formation of the residential environment against the general background of typification and urban approach.

\section{METHODOLOGY}

The main approach to the formation of space from the point of view of aestheticization is confirmed by the historical aspect of the decorative and applied art development and can be formulated by the statement of the English architect O. Pugin: "Create a convenient form, and then decorate it" (Steinbach, Elensky, 2004, p.126). Aesthetics determines the way the objective world is organized. The process of aestheticization can be considered in different aspects, for example, when the individual himself creates in his concept the beauty of the objective world around him, and another approach, when an artist, designer or decorator carries out professional activities already on the basis of existing knowledge and experience. In both cases, we can talk about the formation of the aesthetic in the inner space through cognitive, creative activity. A person's worldview is formed through a style of thinking in science and a style in art. Each stage of society's development is characterized by its own political, economic, and ideological organization. The material embodiment of these social processes is carried out in the spatial structures that surround us. They bear the imprint and style characteristic of each epoch. The entire subject-spatial environment already historically formed and still being created by people, represents a unique materialization of socio-political, ideological, and cultural and aesthetic aspirations of society. "The living environment is a creation and reflection of social being and consciousness, an illustration of the close relationship between the material and spiritual aspects of society's life" (Pankina, 2012, p.65).

\section{DISCUSSIONS}

The material manifestation of aesthetic expressiveness in the residential environment occurs through spatial forms and masses. The process of emotional experiences associated with the perception of these manifestations has a more complex structure than in other types of art. This is due to the duality of the creation of spatial forms. On the one hand, it, the form, arises in the process of functional and technical activity, and on the other hand, the artistic side - it shows aesthetic significance. Thus, aesthetic perception is expressed not only emotionally, but also rationally. In accordance with this, the main task of aestheticizing the environment becomes such a combination of expressive means that will create unity when "architecture becomes sculptural and picturesque, and sculpture and painting - architectural." Architecture will dominate in this unity; sculpture and painting, while preserving their specificity, will belong to architectural and compositional elements.

Spatial arts are widely used to reveal the conceived interior solution. These include drawing, painting, sculpture and objects of decorative and applied art. We suggest paying attention to the need to comply with certain conditions for the design of the space by means of decorative and applied art (Ikonnikov A., 1990, pp. 137-218):

1. Initially, it is necessary to determine the purpose of the space. The works of decorative and applied art (DAA) should fully correspond to the purpose of the subject-spatial environment, complementing and revealing its essence, and thus adapting the space under consideration to specific needs.

2. When organizing interior spaces, it is recommended to use monumental works based on a single stylistic and coloristic solution.

3. Observe the correspondence of the combination of the general interior design and elements (objects, products) of the plot-shaped system of folk art.

4. Use spectacular and high-quality ways of performing decorative and applied art items.

5. The content of the image should expand and deepen the content of the subject itself: a thing becomes 
IJAEDU- International E-Journal of Advances in Education, Vol. VII, Issue 21, December, 2021

artistic when its expressiveness is something more than just the identification of a function.

6. The surrounding things should represent the objective embodiment of a person's feelings, his essence, because things are not only created by man, but under their influence there is a rebirth and development of human feelings.

It should be borne in mind that the uniqueness of the works is not a defining quality, because the relationship of architecture, painting, sculpture, graphics, in interior design is based on the laws of harmony. The crucial importance in this is determined by the functional purpose of the interior. DAA items essentially contribute to the development or transition of the material into the spiritual realm, forming the spiritual world and the sensuality of the living environment, determine the richness of artistic aesthetic perception, have a positive impact on the emotional and sensory sphere, at the same time there is a preservation of the cultural identity of one's own people and awareness of the spiritual value system of cultures of different peoples. In the study of living space, its qualities such as shape, color, iconic models are analyzed first of all. Form and style are concepts in which the material-objective, existential, ontological, external are fixed first of all. the formal side of the aesthetic. But in this externally formal, the internally meaningful, spiritual and psychological always shines through. It is not by chance that the term "expressive" includes the sides of the mutual transition of external and internal, meaningful and formal.

As an example of filling the living environment with means of decorative and applied creativity, we present a student's work on the discipline "Decorative and applied art in the design of the environment" is shown in Fig. 1.

The training sessions are aimed at studying the types of decorative and applied arts, as well as tools and materials used in the creation of DAA items, and techniques for their manufacture. The purpose of the final project work for the semester is to carry out a design project of decorative interior decoration using DAA products (techniques).

Decorative and applied art includes a number of branches of creativity, which are often used to create artistic and utilitarian products for the interior (pillows, furniture, surface decor, etc.). From design to decorative and applied creativity comes more and more advanced techniques and technologies, and decorative and applied art opens up wide artistic possibilities for design. The study of techniques for processing various products and surfaces allows students to develop the ability to implement their creative ideas using various means of expression. Decorating can be an additional part of a design project. The designer can arrange vases, pick up paintings, choose matching accessories in the interior and create decorative objects himself/herself, acting as an applied artist. The formation of the method of creativity in design is carried out at the expense of accumulated decorative and applied art knowledge and techniques of artistic creativity. Having centuries-old folk and national traditions, decorative and applied art is a very strong means of aesthetic development of art and art education in general.

The tasks of the project include: familiarization with the project situation; selection of a suitable stylistic and compositional solution of the project; selection of decorating techniques for the project with a detailed description of the technology of execution; confection of materials and tools for creating decor; development of a design project for interior decoration using elements of decorative and applied art. In order to carry out the decorative filling of the interior, during the analysis of the stylistic and coloristic solutions, students determine the necessary items that contribute to the filling of the selected space from the point of view of utilitarianism and aesthetics. The next stage is the design of the designated objects in the sketch, working out the shape and color in detail. Sketching requires students to imagine how this object will be created in real conditions. At the same stage, the requirements of stylistic conformity, aesthetic harmony and functional expediency of the future object to the existing space must be met. The confection stage includes the selection of materials, tools and the choice of manufacturing technology with a description of the stages of the sequence of execution. With this approach, students begin to perceive the overall stylistic solution of the interior and its individual details more consciously, comparing and connecting the details into a single whole, because the study of various techniques of decorative and applied art takes place in the process of making a product for a residential environment in the material. In the presented project, it was decided to supplement the veranda of a country house with elements of decorative and applied art. With a stylistic decision, it was decided to preserve and develop the concept of eco-style in combination with boho style, which involve the use of natural materials, abundance of light, soft light colors, natural fabrics, lively, green decor. In this example, the following products were selected for the project of decorative filling of the veranda: topiary; hanger in the macrame technique; tablecloth in the macrame technique; hypertuff pot; pillow case in the chenille technique. 


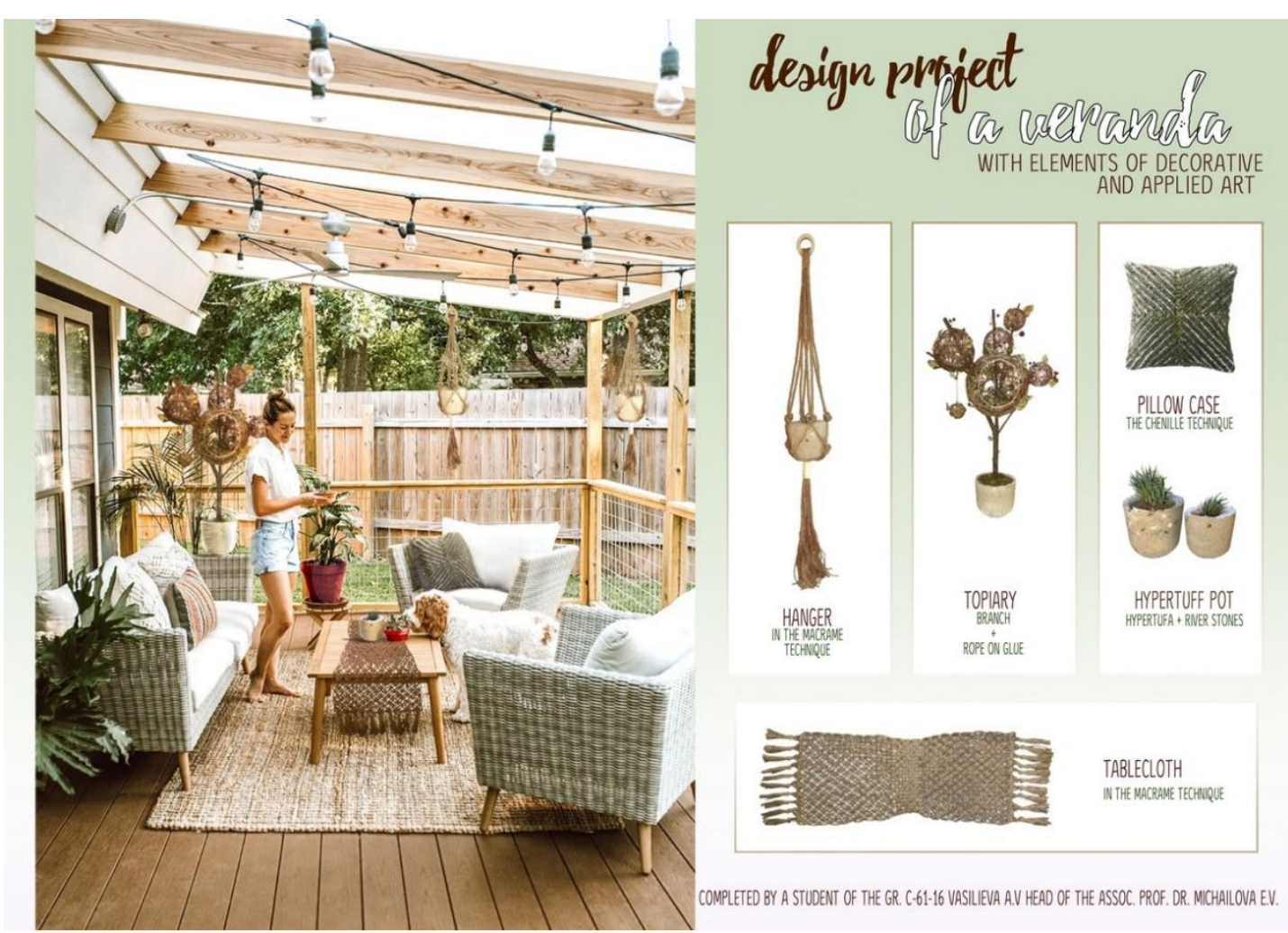

Fig.1. An example of the design project of the decorative design of the environment by means of DAA.

The products developed for the decorative design of the veranda belong to applied types of creativity. Each work is done in a certain DAA technique. The choice of materials, means of artistic processing, compositional and color solutions are directly related to the enrichment of the subject content of the considered space both from the point of view of visual perception and from the utilitarian side.

The structure of the learning process for various types of DAA is as follows:

1. Familiarity with a specific type of decorative and applied art, focusing special attention on the history of the development and significance of products in the subject-spatial environment of a person, as well as the acceptability of this technique in a modern interior.

2. Study of the technique and technology of execution. At this stage, a specific product or technique is selected, materials and tools are considered, the sequence of execution is studied with a detailed description of the features of the execution technique.

3. Production of one work according to the selected sample. According to the catalog or from other sources, the student selects a sample of the product and performs its analogue in the material in the appropriate technique.

4. Individual work of the student to create a DAA product according to the chosen technique. The main requirement for individual work is the ability of the future product to fill the space in terms of utility and aesthetics.

\section{CONCLUSION}

Thus, the aestheticization of space is a complex process of interaction between the sensual and the material. The original verbal image, as a system of interrelated metaphysical representations of taste, beauty of an individual, undergoes the evolution of the life cycle of embodiment under the direct supervision of an artist, designer, decorator. But before considering any concrete facts of creative activity in the field of aestheticization of the spatial environment, it is necessary to touch to some extent on general aesthetic and philosophical points, primarily underlying such a complex phenomenon as culture. In the education of future designers, there is a need to form a clear and sensitive perception of modern reality, a general aspect of its understanding, which determines the final result of the work. For the designer, the idea of the conditions of existence of society, an individual and his spiritual and material life, which are based on a specific worldview, should become fundamental. The motivating movement in professionalization from the point of view of the ability to create a harmonious combination of material objects that fully meet the aesthetic standards of the 
consumer should be the presentation by designers of new requirements to themselves, proceeding from the actual demands of time through aesthetic experience of contact with various forms of art.

\section{REFERENCE LIST}

Ikonnikov A. (1990). Aesthetic values of the subject-spatial environment: scientific edition. M.: Stroyizdat, vol. 336.

Leleko V.D. The space of everyday life in European culture/ (2002). St. Petersburg State University of Culture and Arts. St. Petersburg.

Mayunova O.I. Design as a modern socio-cultural way of aestheticizing the environment and personality. (2000). Tomsk. Bulletin of TSPU 200 Issue 3(19). Humanities Series (special issue), vol. 30-35.

Mikhailova E.V., Andreeva O.P., Grigorieva T.A. Decorative and applied art as a means of forming creative activity of the future designer. (Cheboksary, October 15, 2017). Educational environment today: theory and practice //Cheboksary: CNS "Interactive Plus": materials of the III International Scientific and Practical Conference, vol. 138-141.

Mikhailova E.V., Formation of professional competence in the context of continuous design education ("school-college-university" system) (2013). Diss... Cand. ped. Sciences / Ulyanovsk, vol. 301.

Pankina M.V. Interior and a person: models of interaction: textbook. (2012). Yekaterinburg: Publishing House of the Russian State prof.-ped. University, vol. 135.

Philosophical Dictionary/ed. Ivan Frolov. - 4th ed (1981). Moscow: Politizdat, vol. 445.

Rannev V.R. Interior: a textbook for architectural specialties of universities. (1987). Moscow: Higher School, vol. 232.

Shatunova T.M. The social meaning of the ontology of the aesthetic: dissertation of Dr. philos. Sciences. (2008). - M.: RGE, vol. 347.

Steinbach H.E., Elensky V.I. (2004). Psychology of living space. St. Petersburg: Speech, vol. 239. 